\title{
Variation in Formation of Renal Artery
}

\author{
Ajeevan Gautam, ${ }_{1}^{1}$ Gulam Anwer Khan, ${ }^{1}$ Sameer Timilsina, ${ }^{1}$ Deepesh Dhungel, ${ }^{1}$ Sanjib Kumar Sah ${ }^{2}$ \\ ${ }^{1}$ Department of Anatomy, Chitwan Medical College, Bharatpur-13, Chitwan, Nepal, ${ }^{2}$ Department of Anatomy, \\ Kathmandu University, Birat Medical College, Morang-2,Biratnagar, Nepal.
}

\begin{abstract}
Background: Renal arteries are two large blood vessels branching laterally from the abdominal aorta just below the superior mesenteric artery. The arteries vary in their level of origin and caliber, obliquity and precise relations. Each renal artery is about $6-8 \mathrm{~mm}$ diameter. There is a varying characteristic of these arteries owing to their different course. The aim of the study was to study the variation in the formation of renal artery with its branching pattern using CT Angiography.
\end{abstract}

Methods: The cross sectional study was conducted in the department of Radiology at Chitwan Medical College. CT Angiogram was studied in 17 individuals who attended radiology department for angiography for different suspected abdominal and renal pathology.

Results: Analyzing the result of the angiography, we found the usual branching pattern of renal artery in $70.58 \%$ of the individual, with variations in remaining $29.42 \%$. On studying the number of arteries supplying kidney, artery draining directly to hilum i.e. accessory renal artery was $2.95 \%$. We found the average length of right renal artery ranged between $3.5 \mathrm{~cm}$ to $6.0 \mathrm{~cm}$.

Conclusions: The variations on this large lateral branch of abdominal aorta are common. Surgeons should exclude the possibility of presence of accessory and aberrant renal arteries obstruction prior to the surgical procedure. The awareness about the presence of such variations is important from the academic, surgical and radiological aspect.

Keywords: accessory renal artery; angiography; renal artery; renal surgery.

\section{INTRODUCTION}

Renal arteries are two large blood vessels dividing laterally from the abdominal aorta just below the superior mesenteric artery. ${ }^{1}$ Nearly $25 \%$ of the cardiac output flows through the renal artery for filtration in kidney. ${ }^{2} \mathrm{~A}$ single renal artery to each kidney is present in approximately $70 \%$ of individuals. Near the renal hilum, each artery divides into an anterior and a posterior branch. The anterior division further divides to supply the renal segments. Accessory renal arteries are common and are seen in $30 \%$ of individuals. These artery usually arise from the abdominal aorta above and below the main renal artery and follow the renal hilum. ${ }^{3}$

Each renal artery is about $6-8 \mathrm{~mm}$ diameter. Due to differences in their courses, the characteristics of the renal arteries vary. The right renal artery is 3 to $5 \mathrm{~cm}$ long which arises from the right side of abdominal aorta. It crosses the diaphragmatic pillars, the psoas major and minor muscles to reach the hilum. The left renal artery is about $3 \mathrm{~cm}$ with the same caliber as right artery but arises slightly above the origin of right artery. ${ }^{4}$ Knowledge regarding the anatomical variations of renal vasculature with its origin, course is important to establish the new technique to minimize the additional problem during the surgical procedure. ${ }^{5}$ A study revealed renal arteries occasionally gives inferior phrenic artery. ${ }^{6}$ The aim of the study was to study the variation in the formation of renal artery with its branching pattern using CT Angiography.

\section{METHODS}

This is a cross sectional study conducted at Chitwan Medical College from June 2018 to December 2018. Ethicalapproval was obtained from CMCIRC. A preformed proforma was used to collect the demographic and study variables. Using formula $\mathrm{z}^{2} \mathrm{pq} / \mathrm{d}^{2}$ sample size was calculated and CT Angiogram was studied in 17 individuals who attended radiology department for angiography for suspected abdominal and renal pathology. The patient of renal failure, renal transplantation and with renal congenital anomaly were excluded for the study.

\section{RESULTS}

Analyzing the result of the angiography we found 
that the usual branching pattern of renal artery in $70.58 \%$ of the individual and remaining $29.41 \%$ of

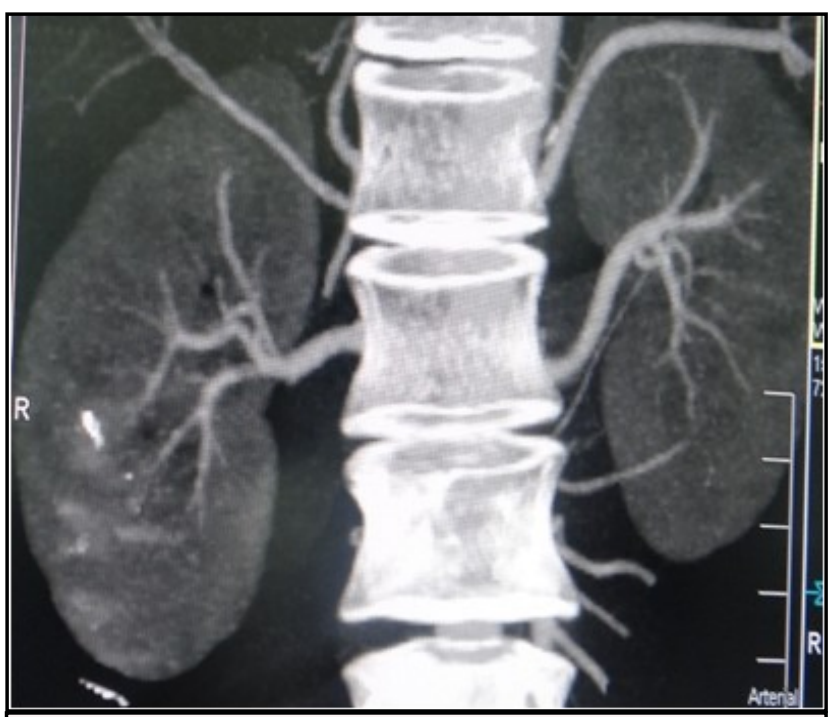

Figure 1. Normal branching pattern.

the subjects showed variations. Among the subjects who showed variation superior or inferior polar artery to be $26.47 \%$ and $2.94 \%$ showed accessory renal artery. The percentage of variation $(70 \%)$ was

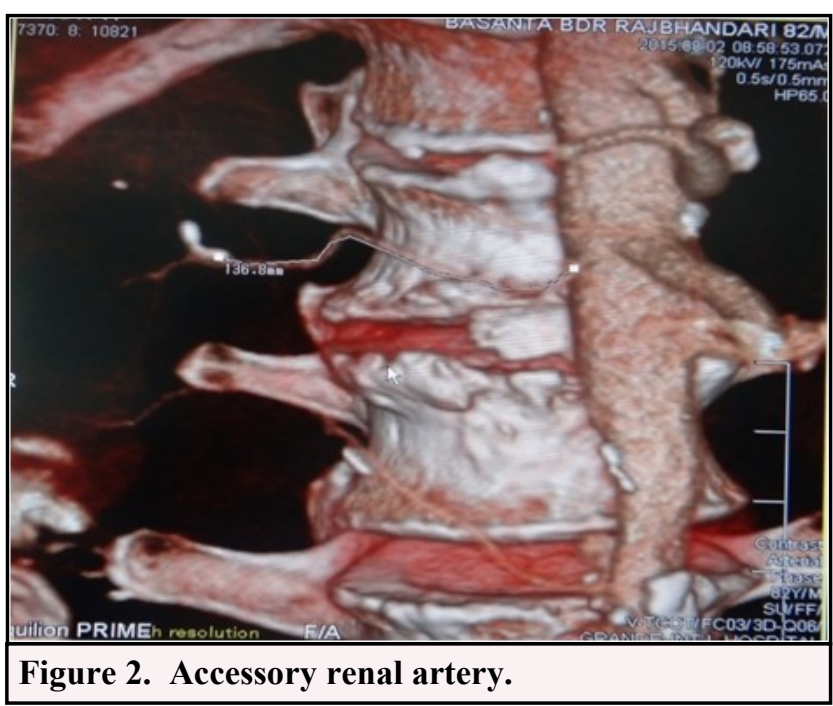

more in male then $(30 \%)$ female. On studying the number of renal arteries supplying each kidney, the

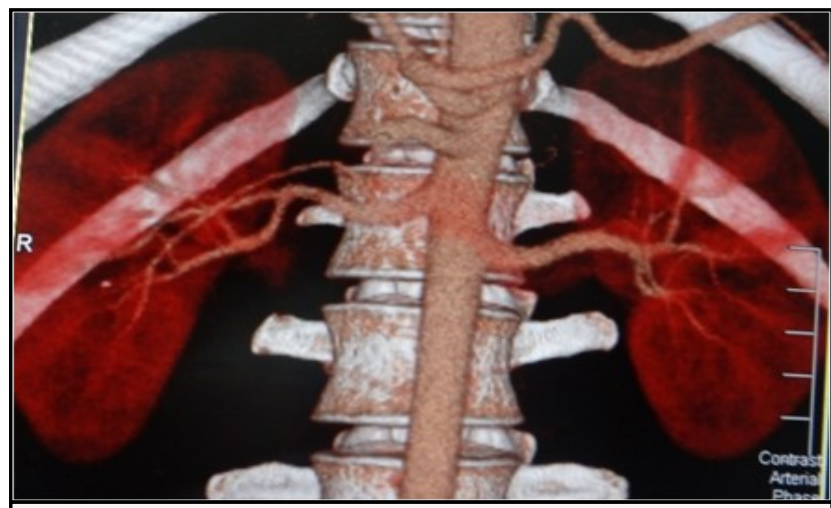

Figure 3. Aberrant Renal Artery. result showed that single renal artery was present in $97.05 \%$, accessory renal artery was found in only $2.94 \%$.

On measuring the length of the renal artery we found following result:

The longest right accessory renal artery was $13.68 \mathrm{~cm}$.On left side one kidney was directly attached to abdominal aorta but most of the accessory artery were of $6 \mathrm{~cm}$ long. Table 1 shows the variations of renal arteries in the study population.

\begin{tabular}{|ll|}
\hline \multicolumn{2}{|l|}{ Table 1. Variation of renal arteries. } \\
\hline Renal artery & Length \\
Right & 3.5 to $13.68 \mathrm{~cm}$ \\
Left & 0 to $6 \mathrm{~cm}$ \\
\hline
\end{tabular}

\section{DISCUSSION}

Renal artery divides laterally from the abdominal aorta just below the superior mesenteric artery. A single renal artery to each kidney is present in approximately $70 \%$ of the individuals. ${ }^{1}$ Accessory renal arteries are common and seen in $30 \%$ of individuals. $^{2}$ These arteries usually arise from the abdominal aorta above and below the main renal artery and follow the renal hilum.

The findings of the study suggest that there are significant variations in the formation and branching pattern of renal artery. Study reported a higher number of normal branching pattern of renal artery among males. The findings in the study documented $70.58 \%$ individual with single renal artery, remaining $29.41 \%$ of the subjects with variations. The result of our study is in accordance to the study of Dyson M. They found single renal artery to each kidney is present in approximately 70 $\%$ of the individuals.

Our study reports $2.94 \%$ of the individual with the accessory renal artery. The findings of our study is similar to the study conducted at AIIMS Rajasthan $(6.68 \%) .{ }^{7}$ Similarly a study conducted at Malaysia observed $4 \%$ of the study population with accessory renal artery. ${ }^{10}$ The result of their study is similar with our result. The reason behind the conformity might be because of the similar ethnic group of people in South East Asia.

A study conducted at Greece reported $72.6 \%$ of the patient with single renal artery. ${ }^{8}$ Similarly a study conducted at Teheran documented accessory artery in $38.2 \%$ of the individuals. Moreover, they spotted that early branching renal artery in $16.5 \%$ of the individuals. ${ }^{9}$ The result of their study is in contrast to ours. Our study documented $97.05 \%$ of the individual had single renal artery. Similarly, the occurrence of accessory renal artery was just $2.94 \%$. Our result shows almost $100 \%$ of the individual with single renal artery. Further studies are recommended with large sample size which 
might give different result. This could as well be the normal trend among Nepalese population, however, generalization cannot be done due to limited sample size.

The CT Angiographic study conducted at Poland established accessory renal artery in $10 \%$ of the cases. ${ }^{11}$ The occurrence of accessory renal artery in our study was just $2.94 \%$. The occurrence of accessory renal artery was nearly similar to our study. This similarity might be because of less sample size in our study. We recommend further studies with large sample size.

\section{CONCLUSIONS}

The variations on this large lateral branch of abdominal aorta are common. Surgeons should exclude the possibility of presence of accessory and aberrant renal arteries obstruction prior to the

\section{REFERENCES}

1. Bannister LH, Berry M, Collins P, Dyson M et al. Grays Anatomy:The anatomical basis of medicine and surgery .38th edition 1815-36.

2. Hall JE. Guyton and Hall Textbook of Medical Physiology.12th Edison:304.

3. Chakraborty S, Pradhan S, Paul M, Majumdar S. Bilateral supernumerary renal arteries in a single cadaver. Int J Anat Var. 2016; 9: 64-66.

4. Soares TRS, Ferraz JS, Dartibale CB, Oliveira IRM Variations in Human Renal Arteries Acta Scientiarum Bio Sci 2013;35(2):277-82.

5. Patil SJ, Mishra S. Inferior renal polar artery and its surgical importance. OA Anatomy 2013 Jun 01;1(2):17.

6. Topaz ON, Topazac A, Pritam R, Polkampally AC, Damianobc T, Christopher A, King A. Origin of a common trunk for the inferior phrenic arteries from the right renal artery: a new anatomic vascular variant with clinical implications. Cardiovascular Revascularization Medicine.2010;11(1):57-62.

7. Potaliya P, Sharma S, Kataria D, et al. Multiple surgical procedure. The awareness about the presence of such variations is important from the academic, surgical and radiological aspect. With an increasing number of cases of renal transplantation, successful graft with multiple arteries may become a routine procedure and failure to restore circulation in the accessory renal artery could lead to ischemia and infarct. Our findings would help surgeons to reduce the incidence of accidents during urological surgery or renal transplantation.

\section{ACKNOWLEDGEMENTS}

We would like to thank the ethical committee of Chitwan Medical College for providing us the consent to conduct this study at this esteemed institute. We would also like to whole heartedly thank the participants of the study without whom the study would not have been possible.

renal vascular variations: A case Series. Int J Anat Var. 2018;11(3):90-92.

8. Gupta A, Gupta R, Singhla KR. The Accessory Renal Arteries : A comparative study in vertebrates with its clinical implications $\mathrm{J}$ CliniDiag Res 2011; 5(5): 970-73.

9. Papaloucas C, Fiska A, Pistevou-Gombaki k et al. Angiographic evaluation of renal artery variation amongst Greeks Aristo UnivMedi J 2007; 34(2): 43-7.

10. Hlaing KP, Das S, Sulaiman IM, Abd-Latiff A, Abd-Ghafar N, Suhaimi FH, Othman F.Accessory renal vessels at the upper and lower pole of the kidney: a cadaveric study with clinical implications. Bratisl Lek Listy. 2010;111(5):308-10.

11. Kornafel O, Baran B, Pawlikowska I, Laszczyński P, Guziński M, Sąsiadek M. Analysis of anatomical variations of the main arteries branching from the abdominal aorta, with 64-detector computed tomography. Pol J Radiol. 2010; 75(2): 38-45.

Citation: Gautam A, Khan GA, Timilsina S, Dhungel D, Sah SB. Variation in Formation of Renal Artery. JCMS Nepal. 2020; 16(1):41-3. 